\title{
Dependence of the Magnetic Properties of Pulsed Laser Deposited Single Crystal MnZn-Ferrite Films on Oxygen Pressure
}

\author{
Conrad M. WILLIAMS1 and Douglas B. CHRISEY ${ }^{2}$
}

1) Morgan State University, Cold Spring Lane and Hillen Road, Baltimore, MD 21239, USA

2) Naval Research Laboratory, 4550 Overlook Avenue, SW, Washington, DC 20375, USA

\begin{abstract}
The authors have examined magnetization $4 \pi \mathrm{M}_{S}$, magnetic anisotropy $\mathrm{K}_{1}$, and coercivity $\mathrm{H}_{\mathrm{c}}$, for a series of single crystal MnZn-ferrite films pulsed laser ablated in oxygen pressures of 15, 30,60 and 90 milli-Torr. The results show that $\mathrm{K}_{1}, 4 \pi \mathrm{M}_{\mathrm{S}}$ and $\mathrm{H}_{\mathrm{C}}$ are very sensitive to the oxygen partial pressure. Depending on the deposition temperature and oxygen pressure, $4 \pi \mathrm{M}_{\mathrm{S}}$ can in some instances have values approximately three times the bulk value of 4,000 Gauss. The magnetic properties appear to be optimum for oxygen pressures between 30 and 60 milli-Torr.
\end{abstract}

\section{INTRODUCTION}

The demands of modern technology for relevant materials has stimulated considerable interest in development of new techniques and processes for the synthesis and modification of materials. Pulsed laser deposition (PLD) is one such technique that is being increasingly used in laboratories to produce high quality thin film structures to address these new demands. The distinctive features of this technique are the true transfer of stoichiometry from the target to the film and the high quality of the deposited films due to the intrinsic presence of ionic components in the laser generated plume. Added features of importance include simplicity, control and the ability to introduce a variety of reactive gases. The control of reactive gas pressure and substrate temperature during deposition allow the synthesis of thin film structures with enhanced electronic, magnetic and structural properties.

PLD perhaps had its most notable success in the growth of high quality single crystal superconducting oxide films [1-3]. Since that time PLD has been used to deposit other materials which include polycrystalline ferroelectric [4] and ferrite films[5].

Ferrites films with their large resistivities and high permeabilities have many applications. These applications include magnetic recording media, non reciprocal planar electronic devices and planar magnetomechanical device applications.

In an earlier investigation we examined the magnetic and structural properties of pulsed laser deposited MnZn-ferrite films epitaxially grown on MgO substrates at an oxygen pressure of 30 milliTorr [6]. The results of that investigation showed the saturation magnetization $4 \pi \mathrm{M}_{\mathrm{S}}$, and first-order magnetocrystalline anisotropy constant $\mathrm{K}_{1}$, depend on intrinsic properties such as composition and cation site occupation. The results also show the uniaxial anisotropy $\mathrm{K}_{\mathrm{u}}$, ferromagnetic resonance linewidth $\Delta H$, and coercive force $\mathrm{H}_{\mathrm{c}}$ depend on the film microstructure. preliminary data in subsequent experiments suggested the magnetic properties may depend on the oxygen pressure during PLD. In this paper we examine the dependence of the magnetic properties of PLD films on oxygen pressure during deposition.

\section{FILM PREPARATION}

The apparatus used to deposit the films is shown in Figure 1. The output from a $\mathrm{KrF}$ excimer laser with an energy density of $\sim 2 \mathrm{~J} / \mathrm{cm}^{2}(248 \mathrm{~nm}$ and $150 \mathrm{~mJ} /$ pulse) operating at $10 \mathrm{~Hz}$ is focused onto a hot isostatically pressed (HIP) $28 \% \mathrm{MnO}$ $18 \% \mathrm{ZnO}-54 \% \mathrm{Fe}_{2} \mathrm{O}_{3}$ target. The target was placed at an angle of $45^{\circ}$ to the laser beam. The laser beam spot is rectangular in shape and is rastered across the ferrite target. The target is rotated at $0.5 \mathrm{~Hz}$ to ensure uniform target wear. The depositions took place in equilibrium oxygen ambient pressures of 15, 30, 60 and 90 milli-Torr. The distribution of laser-ejected material was centered about the normal to the pellet surface and no specula component of ejected material was observed. Target wear and ejected material are minimized by using HIP targets. The vaporized ferrite material was deposited onto a $\mathrm{MgO}$ substrate positioned $\sim 4 \mathrm{~cm}$ away from the center of the ejected material. The substrate was attached to a heated copper block using silver paint to enhance the thermal uniformity of the substrate during deposition. The substrate temperature was monitored and controlled with a chromel-alumel thermocouple embedded on the back surface of the copper block at a position that corresponds to the center of the substrate. However, in spite of this 
precaution, it was estimated that the temperature difference between the copper block and the front surface was between $25-50^{\circ} \mathrm{C}$. Depositions were carried out at substrate temperatures of $300^{\circ} \mathrm{C}, 400$ ${ }^{\circ} \mathrm{C}, 500^{\circ} \mathrm{C}, 600^{\circ} \mathrm{C}, 700^{\circ} \mathrm{C}$ and $900^{\circ} \mathrm{C}$. Following deposition the films were quenched to room temperature by turning off the power to the substrate heater and filling the chamber with 1 atmosphere of oxygen.

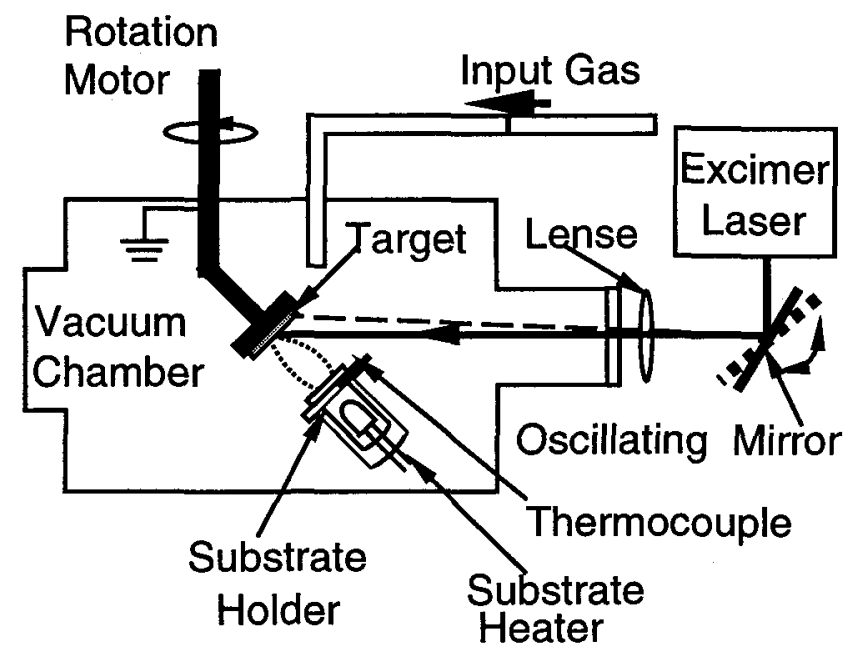

Figure 1. Schematic diagram of the pulsed laser deposition apparatus.

The film microstructure and thicknesses were determined by scanning electron microscopy. The microstructure was similar to that reported in the earlier paper [6]. Films deposited at low temperatures i.e., in the $300{ }^{\circ} \mathrm{C}$ to $400{ }^{\circ} \mathrm{C}$ range, show an epitaxial columnar structure which consist of low angle grain boundaries. This columnar structure develops through the vertical growth of the large number of small crystallites. At higher deposition temperatures, in the $500^{\circ} \mathrm{C}$ to $900^{\circ} \mathrm{C}$ range, there is sufficient surface atomic mobility such that the low angle grain boundary density decreases. At $900^{\circ} \mathrm{C}$, the films show a rather dense microstructure with no observable evidence of grain boundaries. The film thicknesses were determined from SEM micrographs of the film cross section and by Rutherford Backscattering. The thicknesses ranged between $0.5 \mathrm{~mm}-1.0 \mathrm{~mm}$. About 20,000 laser shots were required to obtain these thicknesses.

The film compositions were determined by $\mathrm{x}$-ray fluorescence method using compositions determined by the inductively coupled plasma method as a calibration. The ferrous ion concentration is plotted as a function of oxygen pressure in Figure 2 for substrate temperatures between $300{ }^{\circ} \mathrm{C}$ and $700{ }^{\circ} \mathrm{C}$. The $\mathrm{Fe}^{2+}$ ion concentration increases for all temperatures; peaks at 30 milli-Torr; decreases to a minimum at 60 milli-Torr; then increases for the films deposited at $300^{\circ} \mathrm{C}, 400^{\circ} \mathrm{C}$ and $600^{\circ} \mathrm{C}$.

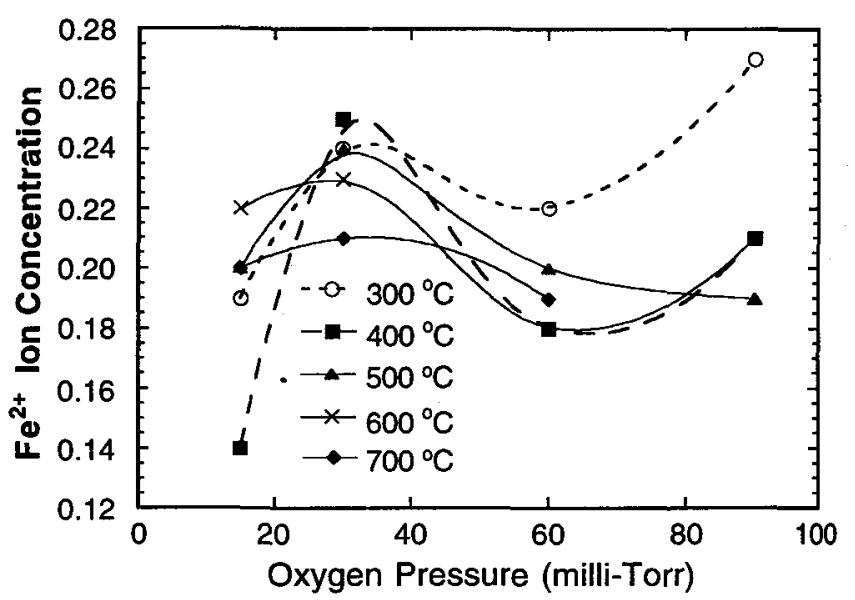

Figure 2. $\mathrm{Fe}^{2+}$ ion concentration plotted as a function of oxygen pressure for various substrate temperatures

\section{MAGNETIC ANISOTROPY}

The first order magnetocrystalline anisotropy constants $\mathrm{K}_{1}$ were obtained from inplane torque magnetometry measurements in the (100) plane using a sensitive torque magnetometer.

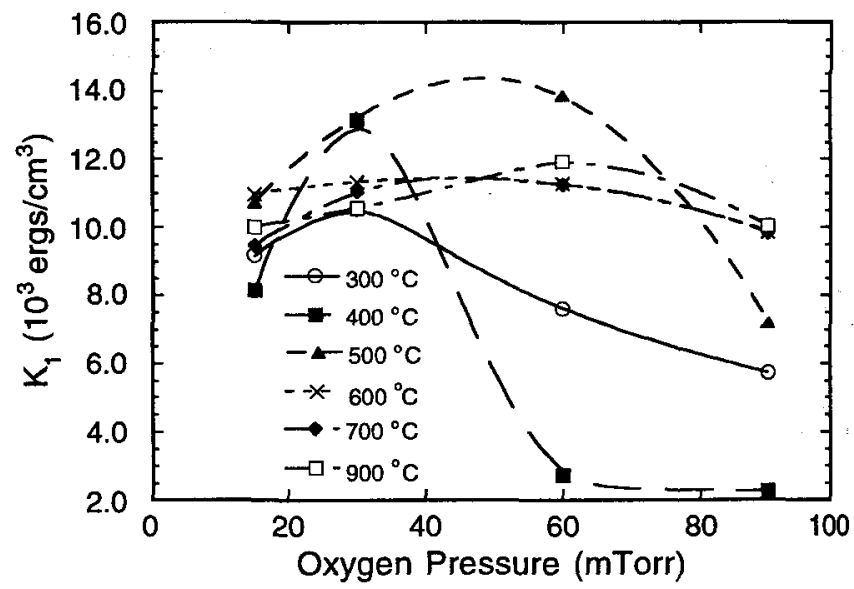

Figure $3 . \mathrm{K}_{1}$ versus oxygen pressure for substrate temperatures between $300^{\circ} \mathrm{C}$ and $900^{\circ} \mathrm{C}$.

The dependence of $\mathrm{K}_{1}$ on oxygen pressure is shown Figure 3 for films deposited at substrate temperatures between $300{ }^{\circ} \mathrm{C}$ and $900{ }^{\circ} \mathrm{C} . \mathrm{K} 1$ peaks at 30 milli-Torr for films deposited at substrate temperatures of $300^{\circ} \mathrm{C}$ and $400{ }^{\circ} \mathrm{C}$ and peaks between 30 and 60 milli-Torr oxygen 
pressure for films deposited at all other substrate temperatures.

In an earlier paper [6] we reported that $\mathrm{K}_{1}$ scales with $\mathrm{Fe}^{2+}$ ion concentration for films deposited at 30 milli-Torr oxygen pressure and that $\mathrm{K}_{1}$ could be accounted for by a single ion anisotropy, resulting from an interaction of the unquenched spin orbitally coupled $\mathrm{Fe}^{2+}$ charge distribution and the trigonal crystal field of the octahedral site. A comparison of the oxygen pressure dependence of $\mathrm{K}_{1}$ (Figure 3 ) and the $\mathrm{Fe}^{2+}$ ion concentration (Figure 2) suggest a similar explanation may, in part, account for the observed $\mathrm{K}_{1}$ in this investigation. However, we feel that other factors may influence $\mathrm{K}_{1}$ such as the ordering of cation vacancies, particularly at the higher oxygen pressures and substrate temperatures[ 7].

\section{MAGNETIZATION AND COERCIVE FORCE}

The room temperature saturation magnetization $\mathbf{M}_{\mathrm{S}}$ and coercivity $\mathrm{H}_{\mathrm{C}}$ were measured in the plane of the film using a vibrating sample magnetometer. The oxygen pressure dependence of

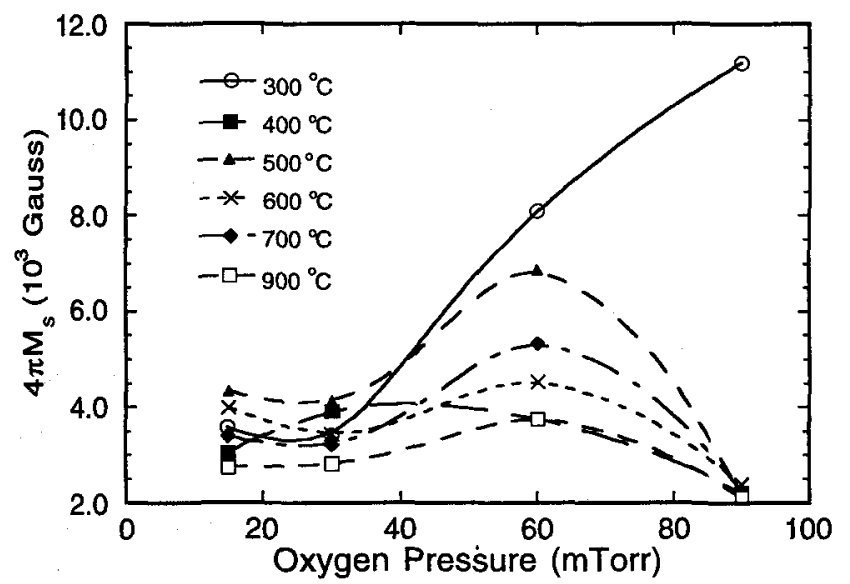

Figure 4. Plot of $4 \pi \mathrm{M}_{\mathrm{S}}$ for single crystalline nominal $\mathrm{Mn}_{0.54}{ }^{\mathrm{Zn}} 0.36^{\mathrm{Fe}_{2.10} \mathrm{O}_{4}}$ films as a function of oxygen pressure for substrate temperatures ranging from $300^{\circ} \mathrm{C}$ to $900^{\circ} \mathrm{C}$.

the saturation magnetization is shown in Figure 4. The measurements show $4 \pi \mathrm{M}_{\mathrm{S}}$ can range from 2,000 to 11,000 Gauss, depending on the oxygen pressure and substrate temperature. This behavior is not characteristic of bulk MnZn-ferrite. The bulk $4 \pi \mathrm{M}_{\mathrm{S}}$ value for $\mathrm{Mn}_{0.54} \mathrm{Zn}_{0.36} \mathrm{Fe}_{2.10} \mathrm{O}_{4}$ is about 3,900 Gauss. The data, with the exception of the films deposited at $300^{\circ} \mathrm{C}$ and $400^{\circ} \mathrm{C}$, also show a slight minima in $4 \pi \mathrm{M}_{\mathrm{S}}$ at 30 milli-Torr; a peak at 60 milli-Torr, with values ranging from 3900 Gauss to 7,000 Gauss; and a minimum value of 2,000 Gauss at 90 milli-Torr for all films except the film deposited at $300{ }^{\circ} \mathrm{C}$ which shows an exceptionally large value of 11,000 Gauss at this pressure.

Previously we reported that $4 \pi \mathrm{M}_{\mathrm{S}}$ scaled with $\mathrm{Fe}^{2+}$ ion concentration. If we compare the temperature dependence of $4 \pi \mathrm{M}_{S}$ and the $\mathrm{Fe}^{2+}$ ion concentration for various oxygen pressures we find, in general, that both the $\mathrm{Fe}^{2+}$ ion concentration and $4 \pi \mathrm{M}_{\mathrm{S}}$ scale reasonably well, which suggest that variations in the $\mathrm{Fe}^{2+}$ ion concentration may in part be responsible for the behavior of $4 \pi \mathrm{M}_{\mathrm{S}}$. Examples of this comparison are shown in Figures 5(a) and 5(b) for films deposited in oxygen pressures of 15 and 60 milli-Torr, respectively.
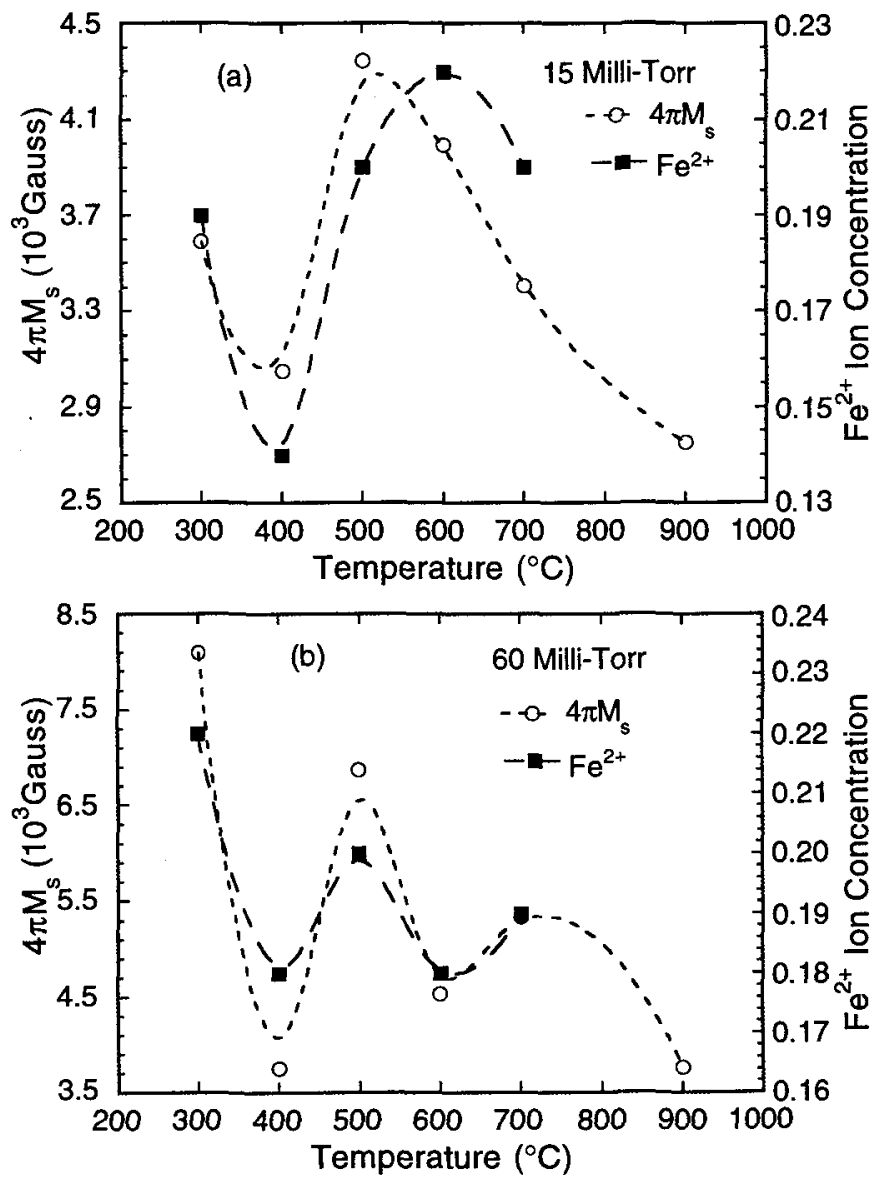

Figure 5. $4 \pi \mathrm{M}_{\mathrm{S}}$ and $\mathrm{Fe}^{2+}$ ion concentration plotted as a function of temperature for oxygen pressures of (a) - 15 milliTorr and (b) - 60 milli-Torr.

The temperature dependence of the coercive force $\mathrm{H}_{\mathrm{C}}$, was examined for films deposited in 
oxygen pressures of $15,30,60$ and 90 milli-Torr (Figure 6). With the exception of the 15 milli-Torr film, $\mathrm{H}_{\mathrm{C}}$ decreases with increasing temperature for all oxygen pressures, reaches a minimum between $500{ }^{\circ} \mathrm{C}$ and $600^{\circ} \mathrm{C}$; then increases slightly. The changes in $\mathrm{H}_{\mathrm{C}}$ is attributed mostly to changes in the microstructure. At low temperatures $\left(300{ }^{\circ} \mathrm{C}\right.$ and $400^{\circ} \mathrm{C}$ ) electron micrographs of the film cross section show a large number of low angle grain boundaries. The large number of low angle grain boundaries and associated dislocations act as pinning sites for domain walls. The pinned domain walls, in turn, contribute to the large $\mathrm{H}_{\mathrm{c}}$ observed. As the temperature is increased, the number of grain boundaries and dislocations are significantly reduced and a lower $\mathrm{H}_{\mathrm{C}}$ is observed. The general increase in $\mathrm{H}_{\mathrm{c}}$ following the minimum is not understood at the present time.

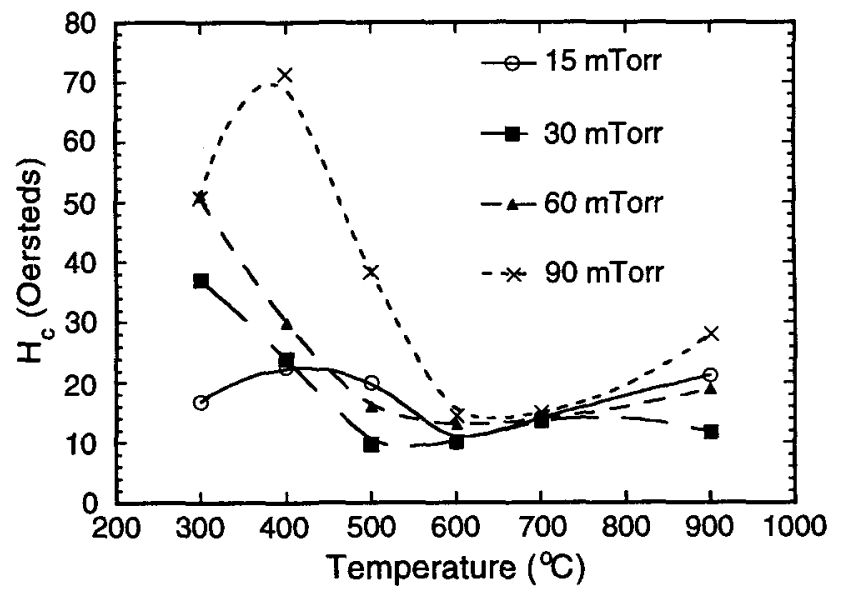

Figure 6. The substrate temperature dependence of $\mathrm{H}_{c}$ for oxygen deposition pressures of 15, 30,60 and 90 milli-Torr.

\section{SUMMARY}

The data presented in this paper suggest that $\mathrm{K}_{1}$ and $4 \pi \mathrm{M}_{\mathrm{S}}$ scale with $\mathrm{Fe}^{2+}$ ion concentration, and that $\mathrm{K}_{1}$ may in part be accounted for by a single ion model at lower substrate temperatures and oxygen pressures. However, the data suggest that other factors may come into play at higher substrate temperatures and oxygen pressures such as the ordering of cation vacancies, in the case of $K_{1}$. The decrease in $4 \pi M_{S}$ to approximately half its bulk value for oxygen pressures of 90 milli-Torr is certainly indicative of the presence of the non magnetic $\alpha-\mathrm{Fe}_{2} \mathrm{O}_{3}$.

In many instances it is difficult to discern the various magnetic phases by $x$-ray diffraction, particularly for epitaxial ferrite films on oriented substrates. However, with the development of brighter $\mathrm{x}$-ray light sources, techniques have be developed that are element- and valence-specific as well as structure sensitive which should be helpful in analyzing the magnetic, structural and intrinsic properties. Two such techniques that in some ways yield complementary information are $\mathrm{x}$-ray magnetic circular dichroism XMCD[8] and X-ray magnetic linear dichroism XMLD [9]. The films used in this investigation are currently under investigation by XMCD. Mossbauer measurements are also planned to complement the XMCD measurements. Upon completion of the structure analyses, we will have a better understanding of the data presented in this paper. The magnetic and structure properties will be correlated and published elsewhere in a longer paper.

\section{ACKNOWLEDGMENTS}

The authors wish to thank the office of Naval Research for their support of this research; Mr. T. Itoh for composition calibrations used in the $\mathrm{X}$-ray flourescence composition measurements; and Professor Keizo Ohta of Aaoyama University, Tokyo, Japan for the HIP MnZn-ferrite targets used in the deposition.

\section{REFERENCES}

T. Venkatesan, X.D. Wu, B. Dutta, A. Inam, M.S. Hegde, D.M. Hwang, C.C. Chang, L. Nazar and B. Wilkens, Applied Phys. Ltrs., 54, 581 (1989).

K. Moorjani, J. Bohandy, F.J. Adrian, B.F. Kim, R.D. Shull, C.K. Chiang, L.J. Swartzendruber and L.H. Bennett, Phys. Rev. B36, 4036 (1987).

G. Koren, A. Gupta, E.A. Giess, A. Segmuller and R.B. Laibowitz, Appl. Phys. Ltrs. 54, 1050 (1989). K.S. Grabowski, J.S. Horwitz and D.B. Chrisey, Ferroelectrics, 116, 19 (1991).

S.B. Ogale, S.M. Kanetar, S.M. Chaudhari, V.P. Godbole, V.N. Koinkar, Sushama Joshi, Rashmi Nawathey, R.D. Vispule and A.R. Moghe, Ferroelectrics, 102, 85 (1990).

C.M. Williams, D.B. Chrisey, P. Lubitz, K.S. Grabowski and C.M. Cotell, J. Appl. Phys.,75, 1676(1994).

E.V. Babkin, K.P. Koval and V.G. Pyn'ko, Sov. Phys. JETP 73, 321 (1991).

G. Schutz, W. Wagner, W. Wilhelm, P. Kienle, R. Zeller, R. Frahm, and G. Materlik, phys. Rev. Lett. 58, 737 (1987).

G. van der Laan, B.T. Thole, G.A. Sawatzky, J.B. Goedkoop, J.C. Fuggle, J.M. Esteva, R. Karnatak, J.P. Remeika and H. Dabkowska, Phys. Rev. B 34, 6529 (1986). 